\title{
Is Gamification a Magic Tool?: Illusion, Remedy, and Future Opportunities in Enhancing Learning Outcomes during and beyond the COVID-19
}

\author{
Hiroko Oe ${ }^{1}$, Takuji Takemoto ${ }^{2}$, Muhammad Ridwan ${ }^{3}$ \\ ${ }^{1}$ Bournemouth University, United Kingdom \\ ${ }^{2}$ University of Fukui, Japan \\ ${ }^{3}$ Universitas Islam Negeri Sumatera Utara, Indonesia \\ hoe@bournemouth.ac.uk; takemoto@u-fukui.ac.jp,bukharyahmedal@gmail.com
}

\begin{abstract}
Gamification in education has been discussed with potential for further implementation at universities; however, practical suggestions concerning which key issues educators need to consider has far not been shared in academia. This study applied a qualitative approach using interview data with 24 students who participated in the business class with games as learning measures. It has found that most of them believed that gamification could be useful in reinforcing key themes and topics after having learnt them through traditional means: They appreciated the games as a supportive measure to 'glue' key knowledge to their learning. A significant drawback that they emphasised was that taking notes is not easy while they are involved in games, which made them unconfident and uncertain about the learning outcome. As a result, a conceptual framework for pedagogy stakeholders was proposed for further discussion of how to design a gamification-based curriculum effectively.
\end{abstract}

\author{
Keywords \\ curriculumdesign; \\ gamification; 00VD-19 \\ lockdown; massively \\ multiplayer online (MM)
}

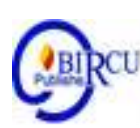

\section{Introduction}

\subsection{Gamification as Attractive Teaching Tool for Business Studies}

ICT-based learning has recently attracted researchers concerning how to implement ICT measures to engage students to enhance learning outcomes. The key aim of this study is to discuss how to engage students in the business study classroom using a framework based on digital gamification, where students can deepen their understanding of contemporary business issues through participating in the learning module. According to Costin et al. (2018), digital simulation of entrepreneurial behaviour develops students' critical thinking and enhances their preparedness for real business activities.

\subsection{Aim and Objectives}

During the coronavirus pandemic, higher education (HE) institutions have been required to introduce new measures to provide safe teaching. This external condition seems to have increased the interest and expectation for gamification which could engage more students in learning by adding excitement and commitment to win the game. Bearing this in mind, the authors implemented a massively multiplayer online (MMO) game during the seminar activities and explored the challenges and potential of gamification in the business education at HE institutions. The game which was used had a virtual economy and community with a large number of participants sharing one server and making decisions on 
the set subject in real time, to which the students joined (Betts \& Rothschild, 2020).

It has been discussed that MMO scheme has positive effect and favourable impact on students' learning process, especially in the contemporary business contexts (Wang et al., 2019). Considering that the current situation necessitates that HE institutions implement ICTbased remote teaching modules; it is especially important to effectively design curricula to engage students and achieve learning outcomes. Therefore, this study aimed to explore students' perspectives and evaluate participants in an online classroom with gamification in a business unit to develop actionable recommendations that could be useful in designing curricula based on the blended learning approach.

\section{Review of Literatures}

\subsection{ICT-Based Learning Modules}

The presence of ICT-related modules in education has experienced rapid growth in the last several years (Atman \& Usluel, 2019; Jha, 2017). Hashimoto (2002), a Japanese specialist in this field, proposed several key takeaways from the implementation of ICTbased modules in HE: (1) the importance of solving the limitation of time and place for both teachers and learners in order to provide a ubiquitous learning paradigm; (2) that learners can state their opinions and ask questions from their keyboards without feeling stressed or pressured; (3) that information is securely and instantaneously transmitted, and learners can independently prepare, review and study whenever they are available; and (4) that electronic teaching materials are accumulative, which can enhance independent learning, generating additional value. The gamification of education has been particularly noted as having a positive impact on active learning (Chitra 2020; Parra-González et al., 2020). Figure 1 depicts the transition from traditional classrooms to ICT-based learning classrooms.

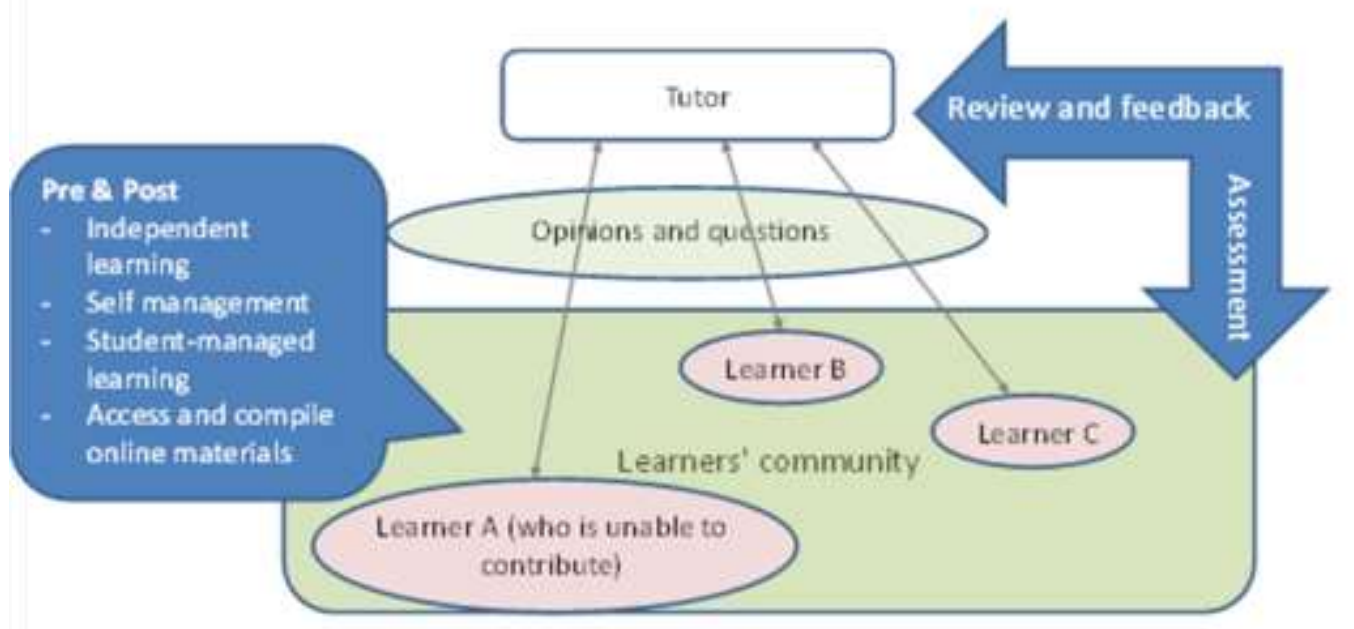

Figure 1. An image of ICT-based learning modules to support individual learners

\subsection{Potential Challenges of Gamification}

After gamification is incorporated into education, it may face challenges, such as failing to gain the attention of students or not being as usefulness as expected. From the perspective of instructional design, some students have raised critical points that should be 
considered in order to develop effective forms of learning. As Figure 2 shows, an MMO scheme enabled students to be successfully included in active learning, while the tutor's responsibility was to assist students, that is, by acting as a facilitator and catalyst.

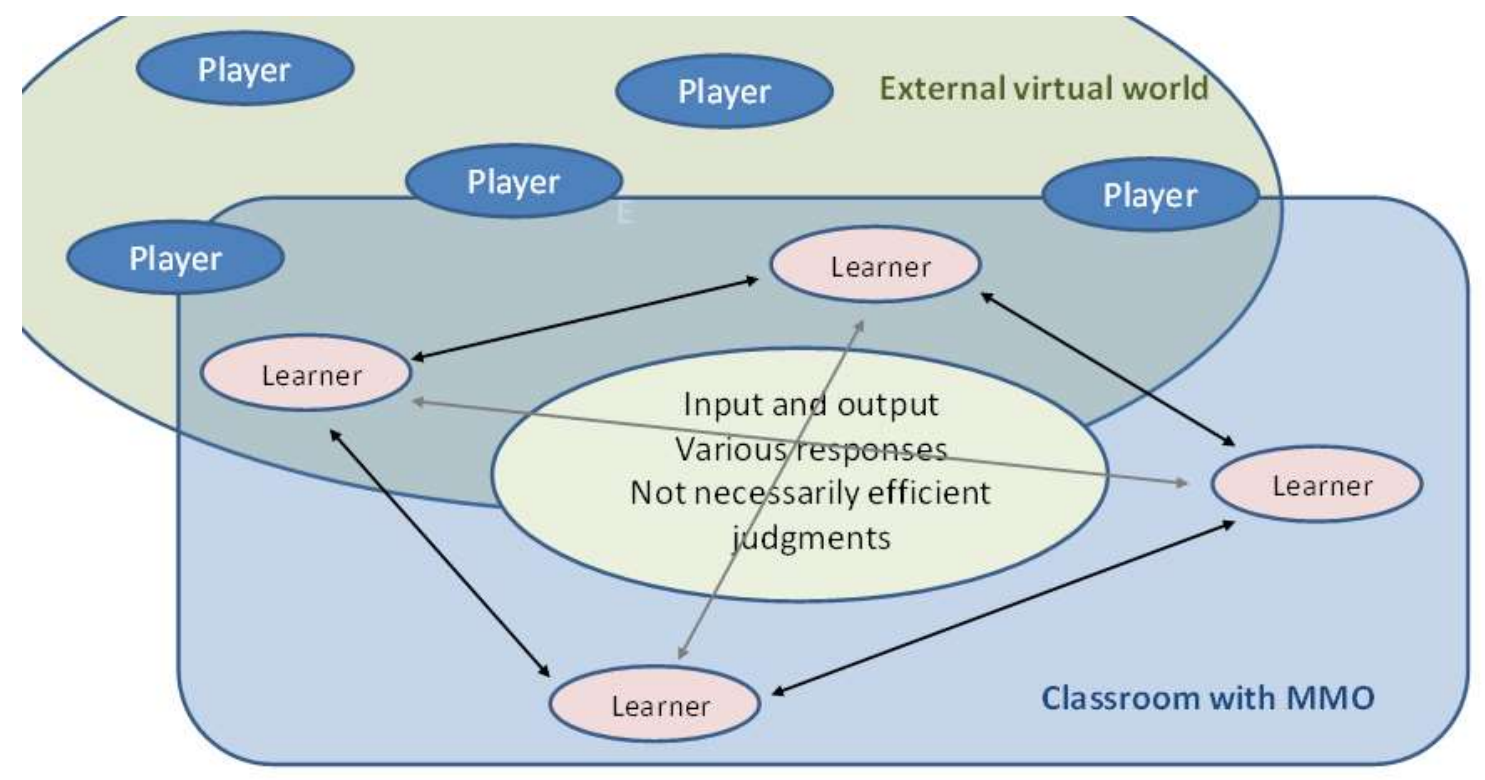

Figure 2. A virtual learning platform with MMO in the classroom

MMO role-playing games for education have been a main theme of gamification (Betts \& Rothschild, 2020; Chen et al., 2020). A disadvantage of ICT education is that it depends on the atmosphere of the class, which is determined by students' level of contribution. If students are not participatory and an educative environment does not arise naturally, it is necessary to create more interesting learning modules. Many researchers have already investigated various forms of education that have used games (Bai et al., 2020; Isabelle, 2020; Ofosu-Ampong, 2020).

In fact, instances of the word 'gamification' have increased recently, but gamification should be the motivation for participants, especially in the context of education. According to Groening and Binnewies (2019), games can be applied to fields of operation management, marketing and other areas. However, empirical research on MMO applications in business studies is lacking.

\subsection{Gamification and EdTech to Support Students' Learning Performance}

Google Trends was used to explore discussion trends by searching the term 'gamification'. The results show that it has rapidly increased since 2011; however, as there are other similar concepts, such as serious games, alternate reality game, edutainment and EdTech, that existed in the past, gamification cannot be said to be a new concept (NTT Data, 2020). Figure 3 demonstrates the instances of the word's use from 2004 to 2020 and indicates that the current trend of gamification has outpaced searches for similar terms, such as 'serious game' and 'alternate reality game', but even so the frequency of the currently trending words is still lower presently compared to a decade ago. 


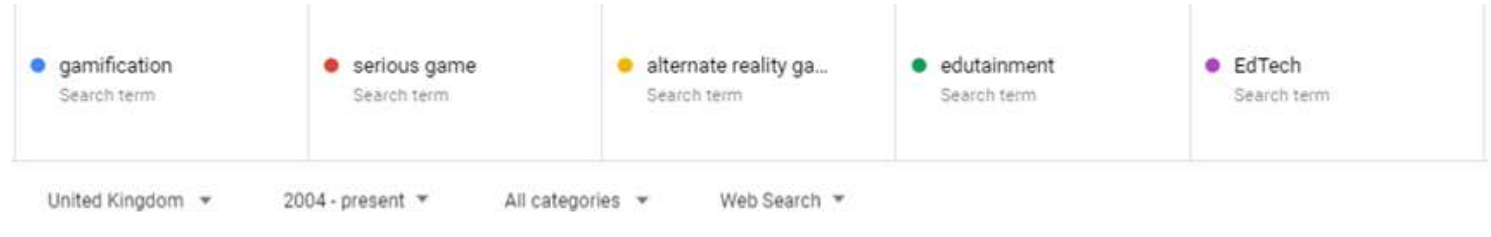

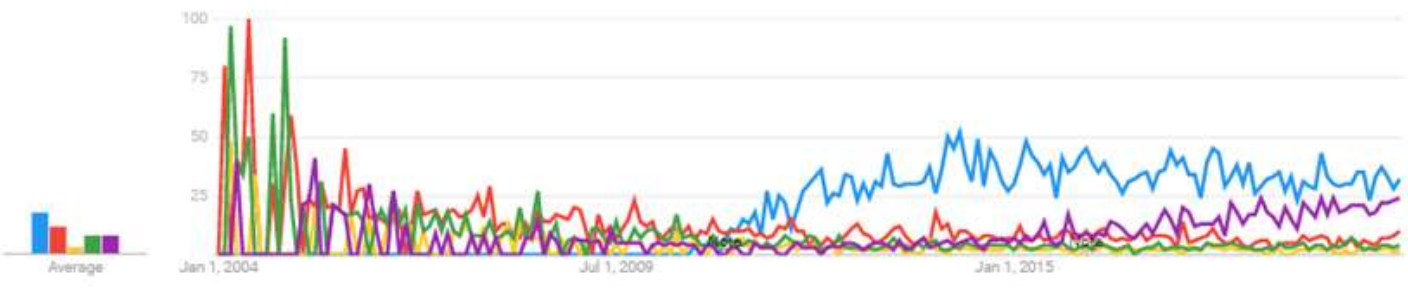

Figure 3. Google Trends' result for 'gamification' and other related keywords in the education context (search on the Google Trends service at https://trends.google.com/trends/?geo=US)

Nonetheless, the rapid increase in use of the keyword 'gamification' is due to successful cases of gamification being incorporated into business classrooms in $\mathrm{HE}$ institutions. Furthermore, this is more than simply the introduction of a buzzword, as evidenced in the fact that it has recently been posted on various sites and appeared in books.

The main features of gamification are its simple rules (goals), ranking (competition) and badges (rewards) (Koivisto \& Hamari, 2019; NTT Data, 2020), all of which are aimed at increasing the motivation of participants (Chou, 2019). In other words, gamification as a simulation of the real business world enables participants to feel and act as if they were behaving as businesspeople in the real world.

On the issue of motivation, from the perspective of instructional design, the attention relevance confidence satisfaction (ARCS) model has been discussed in reference to increasing the motivation of students (Keller, 2016). The model was advocated by John M. Keller, an American educational engineer; it sets out four ways to motivate students to learn. By fulfilling the four dimensions shown below, it has been suggested that participating students learn more actively. Figure 4 demonstrates the four dimensions of the ARCS model.

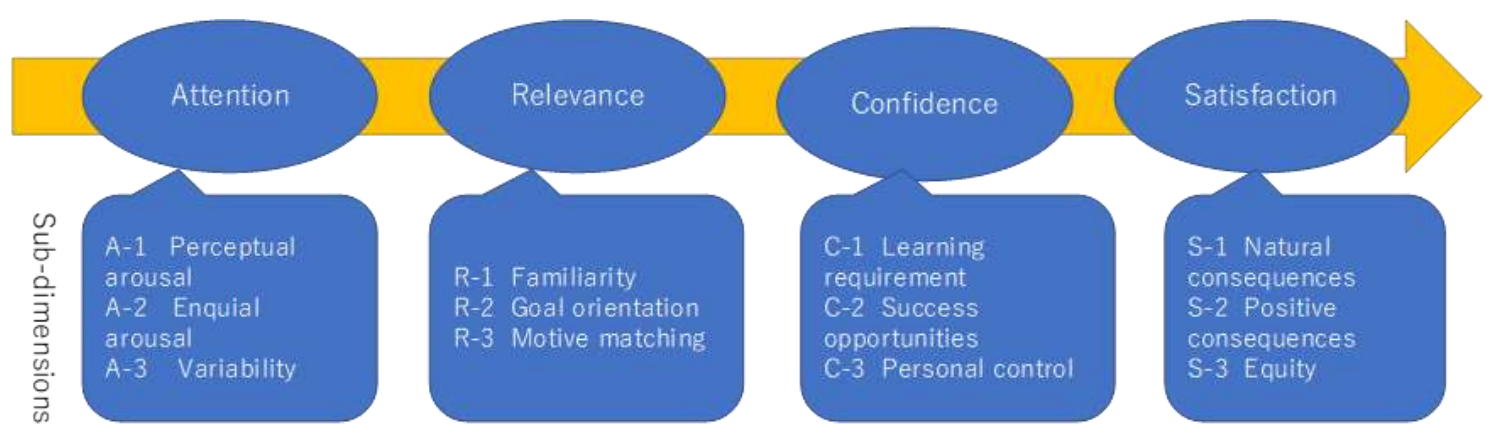

Figure 4. The four dimensions of the ARCS model 
By following the suggested four dimensions of the ARCS model, gamification can be applicable to business education; as noted in the discussion above, gamification can provide actionable stimuli following the four dimensions (Kammunya et al., 2019). Therefore, it would be beneficial to use the proposed dimensions as a guide when designing gamificationbased curricula.

\subsection{Remote Learning during the COVID-19 Lockdown Period}

Due to the current lockdown situation, most universities have switched to online teaching, and people all around the world are now heavily relying on virtual community platforms to connect with classmates, teachers, friends and associates, as individuals adhere to safety protocols and measures such as social distancing (Oe \& Weeks, 2020; Bao et al., 2020). The stressful lockdown conditions due to COVID-19 have been affecting people's psychological wellbeing, which is no different for university students. Hence, it has been on the top of pedagogy agendas to support students especially in the remote learning environment using technologies and virtual learning measures (Almarzooq et al., 2020). Harnessing learning support networks through virtual community platforms could enhance communication among students; in doing so, some key topics have been suggested, such as how to compensate and enhance social connectedness, sense of belongings to the communities and mutual collaborative interaction (Kotera et al., 2020; Nahai \& Kenkel, 2020).

\subsection{Key Takeaways from the Literature Review}

Following the above discussion, key research topics are developed in the context of the COVID-19 lockdown.

Phase 1: Understand: Scenario setting and a variety of events

Phase 2: Experience and explore: Blended learning approach (face-to-face/traditional modules and online gamification); impact of real-time communication and interaction

Phase 3: Evaluate and review: Instant feedback for participants' performance; accumulation and improvement of know-how, complementing textbook learning

During data collection, we guided the discussions using the following guideline (see Figure 5).

Remotellearning circumstances during COVID-19 lockdown:

lack of 'face to face interaction, sense of belonging to learning community, collaborative connectedness'

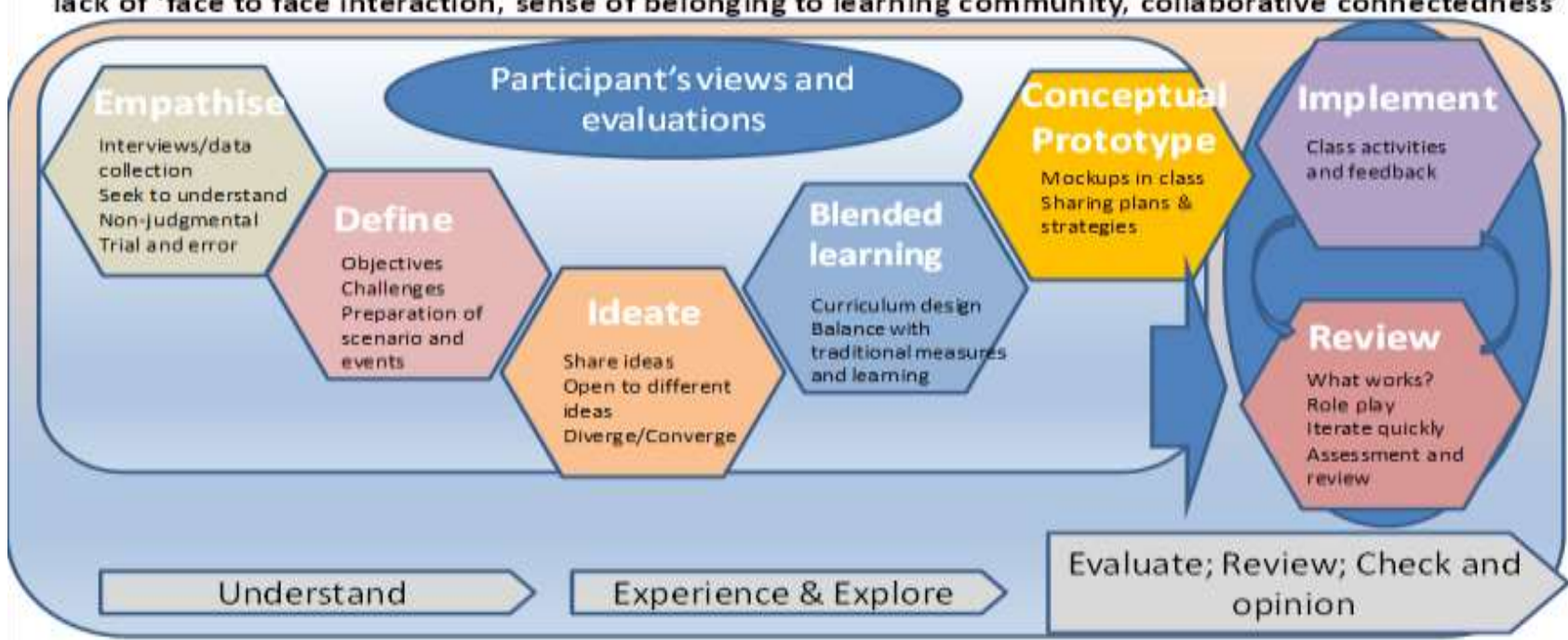

Figure 5. Interview guide: Innovative approach for implementing gamification in classrooms 


\section{Methodology}

\subsection{Research Method and Data Collection}

We interviewed 24 students who participated in the game-based online learning class using a semi-structured interview questionnaire (Tetnowski, 2015). This method allowed us to grasp the hidden thoughts, emotions and behaviours of the interviewees and to address our research aims and objectives. The semi-structured interview questionnaire was based on the key takeaways from the research carried out and was aimed at encouraging the interviewees to express their opinions and feelings in order to provide rich primary data for analysis (Schultze \& Avital, 2011).

The interviewees were presented with a semi-structured questionnaire, which allowed us to change the flexibility levels and structure (Edwards \& Holland, 2013). The perceptionrelated data and information was contextual and situated and required us to guarantee that the related circumstances were brought into focus to produce the situated knowledge (Edwards \& Holland, 2013).

\subsection{Participants}

As the research was aimed at revealing and grasping the students' perceptions towards gamification-based online learning modules, especially under the conditions of the COVID19 situation, voluntary participants were recruited from a class list of students who attended and participated in relevant class activities between April-May 2020, which was when HE institutions were implementing remote learning measures.

To reflect the profile of the student list, a well-balanced sample in terms of both gender and age (12 males and 12 females from a range of age groups) was selected. The participants' details are presented below in Table 1 . The class was a business study unit and included some mature students who already had work experience before attending the postgraduate programme.

Table 1. A list of participants

\begin{tabular}{|l|l|l|}
\hline ID & Gender & Age \\
\hline 1 & Male & 36 \\
\hline 2 & Male & 28 \\
\hline 3 & Male & 26 \\
\hline 4 & Male & 28 \\
\hline 5 & Male & 26 \\
\hline 6 & Male & 32 \\
\hline 7 & Male & 25 \\
\hline 8 & Male & 26 \\
\hline 9 & Male & 30 \\
\hline 10 & Male & 23 \\
\hline 11 & Male & 20 \\
\hline 12 & Male & 23 \\
\hline 13 & Female & 26 \\
\hline 14 & Female & 24 \\
\hline 15 & Female & 25 \\
\hline 16 & Female & 30 \\
\hline 17 & Female & 25 \\
\hline 18 & Female & 26 \\
\hline
\end{tabular}




\begin{tabular}{|l|l|l|}
\hline 19 & Female & 23 \\
\hline 20 & Female & 26 \\
\hline 21 & Female & 26 \\
\hline 22 & Female & 25 \\
\hline 23 & Female & 24 \\
\hline 24 & Female & 29 \\
\hline
\end{tabular}

\subsection{Data Analysis}

The interviews were recorded and transcribed and then were coded. The coding process enabled us to identify patterns and themes within the interviewees' statements (Auerbach \& Silverstein, 2003). The text mining software NVivo 11 was used to develop the codes and to examine the patterns and relationships among the words, which enabled us to analyse the interviewees' profound perceptions and hidden thoughts and ideas. A list of codes was generated and categorised, and the identified key themes and links among the codes were critically analysed with reference to the existing literature. Following this process, the developed findings and the key themes and elements were summarised to form a conceptual framework that can be practically useful for designing curricula to enhance students' active engagement and to achieve learning outcomes.

\section{Discussion}

\subsection{Overview and Evaluation}

As previously discussed, the impact of the implementation of gamification in the classroom can be secured by students' engagement, setting scenarios and a variety of events can support students' active learning, and that real-time communication can enhance students' commitment to activities. The participants, made up of university students who were mostly millennials, were familiar with interactive games, but the more they are ready to play games for the education purpose, they perceive it as one of the games, which are different from game categories that they are familiar with because of the educative elements, such as entrepreneurial contexts and business-related problems being included for students to consider and solve. This paradoxical effect impacted students' learning communities in that they naturally prefer to post their learning outcomes on social media, such as on Snapchat, Facebook and Instagram.

'It was useful for me to be involved in games which was a new experience for me' (Student 10).

'Something new, games in the class is an innovative approach to stimulate our motivation' (Student 28).

'Pre-game preparation was quite useful; it enabled me to understand the stories of the games' (Student 22).

To provide a preparatory background for the class, a guest lecturer was invited to give a talk to introduce the key theme of the role-playing game (i.e. the context of the circular economy and sustainable behaviour communications).

\subsection{Understand: Scenario Setting and a Variety of Events}

This phase is comprised of two key factors (emphasising and defining). Based on these factors, scenario setting and a variety of events were planned and designed. Game scenarios 
should be designed based on these factors. The interviewees stated some observations about this process.

'It was good to participate in the induction session before the game started' (Students 2).

'It was a good experience for me to represent the students to provide our opinions for the preparatory phase while the tutor team was designing the game outline' (Student 18).

'I thought the preparatory phase was already the start of participating in the games' (Student $6)$.

As seen above, the participants appreciated the preparatory process as a chance to deepen their understanding of what they were going to do and the aims of the games.

\subsection{Experience and Explore}

This phase is related to the blended learning approach, that is, how to balance between face-to-face/traditional modules and online gamification and how to enhance real-time communication and interaction to support students' learning performance.

'It was possible to receive instant feedback about the game performance, and also the game logs were open to participants, which made us feel that the process was very transparent' (Student 14).

'At any time, we were told that the programme can be corrected/revised based on our feedback results, which seemed to be one of the good points as we could participate in the game making' (Students 20).

Following the feedback and redesigning of the game, the students felt that they were participating in designing the game. In addition, some student emphasised the importance of focusing on how to validate the blended learning approach.

'We were happy to participate not only in the game itself, but we enjoyed the process more in contributing to the experimenting process of improving the curriculum' (Student 17).

These statements are evidence that the participants appreciated the experience and exploration process as stakeholders; participating in the game was a trigger to engage the students in the learning process.

\subsection{Evaluate and Review}

In terms of reviewing of the games' implementations, a significant issue for the participants was related to the fairness of assessments.

'Instant feedback during participation was helpful, but the game outcome was not suitable for assessment' (Student 19).

'Accumulated game logs and materials are useful; participating in the game was helpful for improving "know-how” to build an effective business plan' (Student 23).

'Overall, participating in the game enhanced my knowledge from my textbook-based experiences' (Student 3).

Almost all the participants had favourable comments to share, and they also pointed out the merit of learning about theories and models in a real business context. 


\subsection{Free Discussion}

This study aims to evaluate the students' observations of the games as a learning module, especially during the COVID-19 lockdown, which was when HE institutions implemented online measures for the delivery of units. During the free discussion time, we asked the interviewees about specific issues or challenges that they faced with respect to learning through games during the lockdown period.

\section{a. Games' Position in the Learning Process during the Lockdown}

During the lockdown period, all classes were switched to remote measures; therefore, it was challenging for tutors to deliver a holistic view of business topics, which is why we implemented business games to support the students' learning.

'Not suitable for building a holistic view, even though participating in a game-based class was fun and easier for me to be engaged' (Student 6).

'It is effective for learning key topics using traditional methods, and I feel more confident that I am learning something' (Student 13).

'Perhaps, some sandwich style of learning could be helpful, textbook-based learning process will be followed by active participation in games, then review and memorise the core key topics, again some discussion in the lecture theatre would be a good module' (Student 21).

\section{b. Assessment of Learning Outcomes}

This point was shared by many students, who insisted that games were effective as a learning tool, but, at the same time, they were concerned about how they would be evaluated and assessed by cooperation during the game.

Gamification raises concerns among students about feedback from their tutors and the fairness of assessment. While it was useful for imprinting knowledge of the theories through practices, some more depth was required while induction session on the specific intended learning outcomes (ILOs) and assessment criteria.

'Assessment and evaluation should be explained more in-depth' (Student 11).

'After all, it is fairer to assess the results learned by gamification with comprehensive exams and reports' (Student 20).

\section{c. How to Enhance Learning during the COVID-19 Lockdown}

Sharing the material does not lead to substantial learning, even if the students can save, keep and review the game logs. The students seem to prefer to learn with notes.

'I'm worried about not being able to take notes during the game' (Student 3).

'To the last, I strongly feel that the game is an auxiliary position' (Student 17).

Even though the students viewed the position of games as a secondary tool in the learning process, it is obvious that they appreciate the innovative approach to enhance their learning motivation during the current remote learning period.

'However, the opportunity of innovative learning measures can be evaluated' (Student 16).

'As a learning process, still participating in games is momentary, and I felt to be connected with classmates and tutors while participating in the game' (Student 24).

'It worked well to motivate me to participate in the live class as participating in the game is quite new and stimulating for my learning motivation' (Student 7). 
As a result, it is the accumulation and improvement of the know-how of educational institutions that enables a rise in the quality of education without face-to-face interaction. Being able to connect with a large number of people simultaneously creates a new educational communication space. Not only the teacher but also the students can mutually share experiences, enquiries and evaluations of the games' practices.

\section{Conclusion}

\subsection{Overall Discussion}

In HE institutions, it has been a long-standing challenge to teach economics effectively, whereby students can gain experience and use that experience to guide them in learning practical strategic tools in the real business world (Foray, 2004; Sitorus et al., 2019). More specifically, Negru (2010) suggested that learning economics should be based on the critical thinking approach, which can lead to better learning outcomes for students. As noted, gamification has attracted the attention of researchers and pedagogists as a means to support students' learning, and this study has evaluated students' observations and evaluations of their participation in games to develop actionable implications with recommendations to enhance the effectiveness of gamification in economics education (Hamari et al., 2015; Kim et al., 2018). This theme should be mandatory, especially during the COVID-19 lockdown, because it encourages researchers and pedagogists to implement virtual measures to support students' learning performance.

\subsection{A Proposition of a Conceptual Framework}

This study also explored the effectiveness of MMO games in business-related units. This system is ideal not only because learners acquire knowledge through lectures but also because they can gain practical experience through simulated business activities in the behavioural contexts of contemporary enterprises (Adedokun \& Kayode, 2019; Rocha et al., 2020). The usefulness of peer-to-peer assessment has also been discussed and evaluated in the context of remote learning (Danka, 2020).

According to Hill and Brunvan (2018), gamification should be considered and strategically implemented in curricula to support students' learning. Therefore, it is the responsibility of tutors to maximise its positive impact as a tool to make the learning process attractive, fair and engaging (Whitton \& Langan, 2019; Syakur et al., 2020). Digital gamification is a theme to focus on to deepen students' understanding of the contemporary technological theme through participating in the learning module (Hung, 2018). Adding to the discussion, Leitão (2018) also suggested that gamification in teaching can support the development of design thinking attitudes among students through interacting with environmental stimuli for their learning motivation (Junior et al., 2020; Thompson \& Schonthal, 2020).

Gamification-based modules were well-liked by the participants throughout the lockdown duration. A positive impact of this method was that the students could control their learning process and were happy to take ownership of it, which enhanced their motivation to carry out more research on the topics that they were learning about through the games. Furthermore, some students who were looking for job opportunities stated that they talked about how they had learnt to enhance their capability in the virtual community to be employed in real business contexts, which emphasises the positive influence of participating in the games during class activities. 
Gamification provides a good platform for student engagement, motivating and enabling them to focus on contemporary business issues; however, some more instruments and preparation is essential to make it work as a co-creation paradigm for pedagogy stakeholders. Furthermore, this learning/educating process based on gamification should be developed in the scope of supporting students' design thinking perspectives, which, in turn, enhance the innovative behaviour of organisations (Lin et al., 2020).

Based on the above discussion, a conceptual model with recommendations is proposed, as shown in Figure 6. This framework proposes steps for design thinking in making a gamification-based module effective and in providing key themes for further discussion with pedagogy stakeholders (Junior et al., 2020). As indicated, implementation of gamification is not a magic tool as it is, the well thought-out planning and reviewing process is critical to be valuable as one an effective teaching method.

\section{Gamification design during COVID-19 lockdown:}

\section{Enhance (1) collaborative learning motivation \& (2) sense of belonging to learning community}

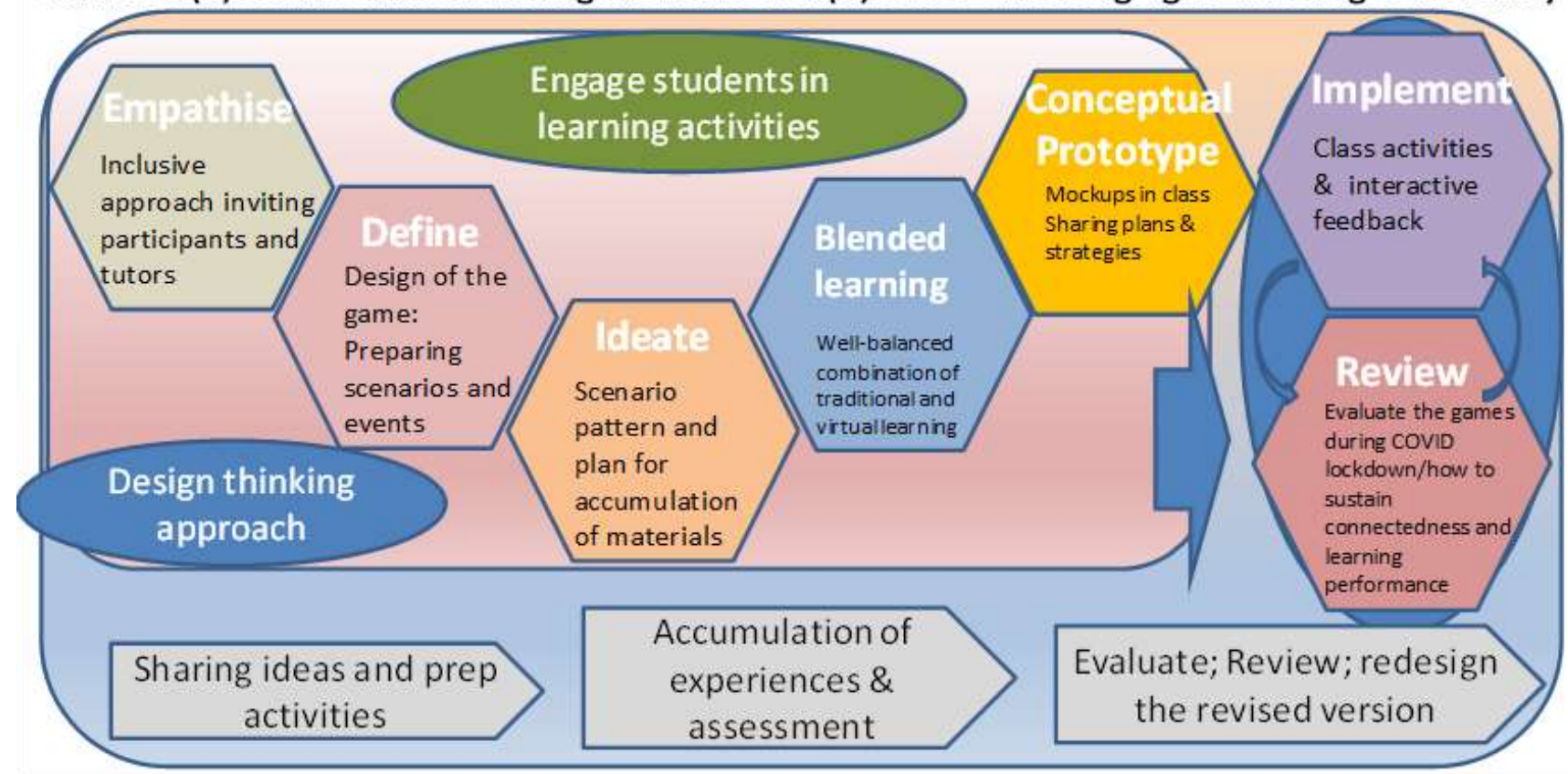

Figure 6. Conceptual framework with design thinking steps and recommendations for a remote learning module

\subsection{Further Research Opportunities}

This study aimed to provide a holistic view on how to implement and maximise the effectiveness of gamification in business education. The outcome of the interviews reveals some issues that tutors need to consider when designing a curriculum based on gamification. Even though students appreciate the instructiveness of ICT-based gamification as a learning module, they are nonetheless cautious about the possible lack of holistic learning and prefer to take memos using pen and paper. Gamification in education has been recently attracting the attention of researchers and pedagogists as if it would be a magic tool; however, practical guidance for how to design and implement gamification has not yet been proposed. This study's contribution is to provide practical implications with recommendations for $\mathrm{HE}$ pedagogists in designing effective learning modules based on ICT and gamification to 
enhance students' learning outcomes, especially considering the new normal of the blended learning approach.

To further our research, we need to design hypotheses based on the experiences and knowledge from the gamification-based modules to be verified with primary data to develop more robust implications for pedagogy stakeholders to contribute to the designing of effective curricula in the future. With the quantitative approach, other researchers should also be able to accumulate our experiences and data from the cases of gamification in the teaching module to evaluate and discuss the process proposed in Figure 6; doing so would enhance our discussion outcomes to contribute more effectively to the design of curricula.

\section{References}

Adedokun, M. O., \& Kayode, G. M. (2019). Local Leadership Styles and Community Development: A Study of the Irasa Community of Ado-Ekiti, Nigeria. Budapest International Research and Critics in Linguistics and Education (BirLE) Journal, Vol.2, No. 4, pp.27-31.

Almarzooq, Z., Lopes, M., \& Kochar, A. (2020). Virtual learning during the COVID-19 pandemic: a disruptive technology in graduate medical education, Journal of the American College of Cardiology (in-printing)

Atman Uslu, N., \& Usluel, Y. K. (2019). Predicting technology integration based on a conceptual framework for ICT use in education. Technology, Pedagogy and Education, Vol. 28, No.5, pp.517-531.

Auerbach, C., \& Silverstein, L. B. (2003). Qualitative data: An introduction to coding and analysis (Vol. 21). NYU press.

Bai, S., Hew, K. F., \& Huang, B. (2020). Is gamification "bullshit"? Evidence from a metaanalysis and synthesis of qualitative data in educational contexts. Educational Research Review, 100322 (in-printing).

Betts, A. L., \& Rothschild, M. K. (2020). Massively Multiplayer Online Games as Spaces for Metacognition and Self-Regulated Learning. In Global Perspectives on Gameful and Playful Teaching and Learning (pp. 78-104). IGI Global.

Chen, A., Mari, S., Grech, S., \& Levitt, J. (2020). What We Know About Massively Multiplayer Online Role-Playing Games. Harvard Review of Psychiatry, Vol. 28, No. 2, pp.107-112.

Chitra, K. (2020). Adoption of Gamification tool in Higher Education: An empirical study. Studies in Indian Place Names, Vol. 40, No. 3, pp.3132-3146.

Chou, Y. K. (2019). Actionable gamification: Beyond points, badges, and leaderboards. Packt Publishing Ltd.

Costin, Y., O'Brien, M. P., \& Slattery, D. M. (2018). Using simulation to develop entrepreneurial skills and mind-set: An exploratory case study.

Danka, I. (2020). Motivation by gamification: Adapting motivational tools of massively multiplayer online role-playing games (MMORPGs) for peer-to-peer assessment in connectivist massive open online courses (cMOOCs). International Review of Education, Vol. 66, No. 1, pp.75-92.

Edwards, R., and Holland, J., 2013. What is qualitative interviewing? A\&C Black.

Foray, D. (2004). Economics of knowledge. MIT press.

Groening, C., \& Binnewies, C. (2019). “Achievement unlocked!"-The impact of digital achievements as a gamification element on motivation and performance. Computers in Human Behavior, Vol. 97, pp.151-166. 
Hashimoto, J. (2002). "Role of Staffand System,"Ybshiaki Ohara," Universityclass Uses ICT, Tamagawa University Press.

Hill, D., \& Brunvan, S. (2018). Gaming the System: Helping Students Level up Their Learning. International Journal of Teaching and Learning in Higher Education, Vol. 30 No. 1, pp.70-79.

Hamari, J., Huotari, K., \& Tolvanen, J. (2015). Gamification and economics. The gameful world: Approaches, issues, applications, pp.139.

Hung, A. C. Y. (2018). Gamification as Design Thinking. International Journal of Teaching and Learning in Higher Education, Vol. 30, No. 3, pp.549-559.

Isabelle, D. A. (2020). Gamification of Entrepreneurship Education. Decision Sciences Journal of Innovative Education, Vol. 18, No. 2, pp.203-223.

Jha, A. (2017). ICT Pedagogy in Higher Education: A Constructivist Approach. Journal of Training and Development, Vol. 3, pp.64-70.

Junior, W. G., Marasco, E., Kim, B., \& Behjat, L. (2020). Supporting Design Thinking Through a Game-Based Pedagogy in Entrepreneurship Education. Papers on Postsecondary Learning and Teaching, Vol. 4, pp.39-49.

Kamunya, S., Maina, E., \& Oboko, R. (2019, May). A Gamification Model For E-Learning Platforms. In 2019 IST-Africa Week Conference (IST-Africa) (pp. 1-9). IEEE.

Keller, J. M. (2016). Motivation, learning, and technology: Applying the ARCS-V motivation model. Participatory Educational Research, Vol. 3, No. 2, pp.1-15.

Kim, S., Song, K., Lockee, B., \& Burton, J. (2018). What is gamification in learning and education?. In Gamification in learning and education (pp. 25-38). Springer, Cham.

Koivisto, J., \& Hamari, J. (2019). The rise of motivational information systems: A review of gamification research. International Journal of Information Management, Vol. 45, pp.191-210.

Kotera, Y., Green, P., Rhodes, C., Williams, A., Chircop, J., Spink, R., Rawson, R. \& Okere, U. (2020). Dealing with isolation using online morning huddles for university lecturers during physical distancing by COVID-19 field notes, Available at: https://derby.openrepository.com/handle/10545/625008 [Accessed 11 August 2020]

Leitão, J. (2018). Open Innovation Business Modeling: Gamification and Design Thinking Applications. Springer.

Lin, L., Shadiev, R., Hwang, W. Y., \& Shen, S. (2020). From Knowledge and Skills to Digital works: An Application of Design Thinking in the Information Technology Course. Thinking Skills and Creativity, 100646 (in-printing).

Nahai, F., \& Kenkel, J. M. (2020, June). Accelerating Education During COVID-19 Through Virtual Learning. In Aesthetic Surgery Journal Open Forum (Vol. 2, No. 2, p. ojaa023). US: Oxford University Press.

Negru, I. (2010). Plurality to pluralism in economics pedagogy: the role of critical thinking. International Journal of Pluralism and Economics Education, Vol. 1m No. 3, pp.185193.

NTT Data (2020) Practice of learning by utilizing gamification: From professor to hands-on learnin, Available at: http://www.intellilink.co.jp/article/column/itsm-sp.html [Accessed 21 July 2020]

Oe, H. (2020). Discussion of digital gaming's impact on players' well-being during the COVID-19 lockdown. arXiv preprint arXiv:2005.00594.

Oe, H., \& Weeks, M. (2020). How to Support Vulnerable Citizens during the COVID-19 Lockdown: A Community Initiative from Ubiquitous Network Perspectives. Budapest International Research and Critics Institute (BIRCI-Journal): Humanities and Social Sciences, Vol. 3, No. 2, pp.1369-1377. 
Ofosu-Ampong, K. (2020). The Shift to Gamification in Education: A Review on Dominant Issues. Journal of Educational Technology Systems, 0047239520917629 (in-printing).

Parra-González, M. E., López Belmonte, J., Segura-Robles, A., \& Fuentes Cabrera, A. (2020). Active and Emerging Methodologies for Ubiquitous Education: Potentials of Flipped Learning and Gamification. Sustainability, Vol. 12, No. 2, pp.602.

Reynolds, K. M., Roberts, L. M., \& Hauck, J. (2017). Exploring motivation: integrating the ARCS model with instruction. Reference Services Review. Vol. 45, No. 2, pp.149-165.

Rocha, E. M., Pereira, G. M., \& Pacheco, D. (2020). The role of the predictive gamification to increase the sales performance: a novel business approach. Journal of Business \& Industrial Marketing, Vol. 35/5, pp.817-833

Schultze, U. and Avital, M., 2011. Designing interviews to generate rich data for information systems research, Information and organisation, Vol. 21, No. 1, pp.1-16.

Sitorus, H., Nugrahadi, E. W., \& Budiarta, K. (2019). The Effect of Learning Strategy and Thinking Ability on The Students' Learning Outcomes in Economics Subject of XI Social Students in Senior High School State 1 in Pematang Siantar. Budapest International Research and Critics in Linguistics and Education (BirLE) Journal, Vol. 2, No. 4, pp.451-460.

Syakur, A., Susilo, T. A. B., Wike, W., \& Ahmadi, R. (2020). Sustainability of Communication, Organizational Culture, Cooperation, Trust and Leadership Style for Lecturer Commitments in Higher Education. Budapest International Research and Critics Institute (BIRCI-Journal): Humanities and Social Sciences, Vol. 3, No. 2, pp.1325-1335.

Tetnowski, J., 2015. Qualitative case study research design. Perspectives on Fluency and Fluency Disorders, Vol. 25, No. 1, pp.39-45.

Thompson, L., \& Schonthal, D. (2020). The social psychology of design thinking. California Management Review, Vol. 62, No. 2, pp.84-99.

Wang, D., Yang, Z., \& Ding, Z. (2019). Is Sociability or Interactivity more Effective for Enhancing Performance? Findings from a Massively Multiplayer Online Role-Playing Game. Journal of Interactive Marketing, Vol. 48, pp.106-119.

Whitton, N., \& Langan, M. (2019). Fun and games in higher education: an analysis of UK student perspectives. Teaching in Higher Education, Vol. 24, No. 8, pp.1000-1013. 